\title{
Agaricus blazei Murill enhances doxorubicin-induced apoptosis in human hepatocellular carcinoma cells by NFkB-mediated increase of intracellular doxorubicin accumulation
}

\author{
JONG SEOK LEE and EOCK KEE HONG \\ Department of Bioengineering and Technology, Kangwon National University, Chuncheon 200-701, Republic of Korea
}

Received June 21, 2010; Accepted August 12, 2010

DOI: $10.3892 /$ ijo.2010.852

\begin{abstract}
It has been demonstrated that the Agaricus blazei Murill (ABM) mushroom, which primarily consists of polysaccharides, possesses anti-tumor activities. However, the mechanisms by which ABM inhibits human hepatocellular carcinoma growth remain unknown. Our study demonstrates that ABM acts as an enhancer to sensitize doxorubicin (Dox)mediated apoptotic signaling, and this sensitization can be achieved by enhancing intracellular Dox accumulation via the inhibition of $\mathrm{NF \kappa B}$ activity. These findings suggest that ABM, when combined with low doses of Dox, has the potential to provide more efficient therapeutic effects against drug-resistant human hepatocellular carcinoma.
\end{abstract}

\section{Introduction}

Hepatocellular carcinoma (HCC) is the fifth most common cancer and the fourth leading cause of cancer-related mortality worldwide, with the highest incidence in Asia (1). Despite surgical management and application of non-surgical therapeutic modalities, the incidence of HCC continues to rise (2). Doxorubicin (Dox) is an effective chemotherapeutic drug for the treatment of patients with HCCs (3). However, Dox has been shown to cause development of drug resistance to apoptosis, thereby limiting successful outcomes of cancer chemotherapy (4). One feature that cytotoxic treatments of cancer have in common is their activation of the nuclear transcription factor $\kappa \mathrm{B}(\mathrm{NF} \kappa \mathrm{B})$, which regulates cell survival $(5,6)$. NFKB activation suppresses the apoptotic potential of chemotherapeutic drugs and contributes to resistance. In this approach, the ability to sensitize apoptotic signaling pathways implicated in enhancing chemosensitivity of chemotherapeutic drugs has important therapeutic implications (7).

Correspondence to: Professor Eock Kee Hong, College of Engineering, Department of Bioengineering and Technology, Kangwon National University, 192-1 Hyoja-2-dong, Chuncheon-si, Gangwon-do 200-701, Republic of Korea

E-mail: ekhong@kangwon.ac.kr

Key words: Agaricus blazei, doxorubicin, apoptosis, hepatocellular carcinoma, NFKB
$\mathrm{NF}_{\kappa} \mathrm{B}$ is a heterodimeric complex composed of two subunits p50 and p65. It is normally present in the cytoplasm in an inactive state in complex with an inhibitory subunit of $\kappa \mathrm{B}(\mathrm{I} \kappa \mathrm{B} \alpha)$. Upon phosphorylation and subsequent degradation of $\mathrm{I} \kappa \mathrm{B} \alpha$, a nuclear localization signal on the p50-p65 heterodimer is exposed, leading to nuclear translocation of NFKB. The p50-p65 heterodimer binds to specific DNA sequences on the promoter of target genes $(8,9)$. BAY 11-7082 is shown to inhibit IкB $\alpha$ phosphorylation thereby blocks proteasomal degradation of $\mathrm{I}_{\kappa} \mathrm{B} \alpha$, and hence sequestering $\mathrm{NF} \kappa \mathrm{B}$ in the cytoplasm in an inactivated state (10). Treatment of cellpermeable inhibitor peptide (NFKB SN50) has shown to inhibit nuclear translocation of NFKB and to inhibit NFKBdependent reporter gene transcription (11).

In recent years many natural polysaccharides and polysaccharide-protein complexes, isolated from mushrooms, have been used as therapeutic drugs (12). Many studies have demonstrated that polysaccharides from basidiomycetes mushrooms had highly beneficial therapeutic effects including: i) preventing oncogenesis after the administration of peroral medications developed these mushrooms or their extracts, ii) direct anti-tumor activity against various tumors, iii) synergistic anti-tumor activity in combination with chemotherapy, and iv) preventive effects on tumor metastasis (13-16). Data on polysaccharides isolated from Agaricus blazei Murill (ABM) are highly impressive, and these polysaccharides show promise for use as cancer therapeutics. Studies have shown that $\mathrm{ABM}$ extracts strongly suppress the growth of various tumors in vitro and in vivo $(17,18)$. However, the molecular signaling involved in ABM-mediated anti-tumor activity has never been investigated in HepG2 human hepatocellular carcinoma cells.

Apoptosis (programmed cell death), is an important physiological process of cell death and occurs during tissue remodeling, immune regulation and tumor regression. Most of the chemotherapeutic drugs kill cancer cells by inducing apoptotic death pathways (19). Cells undergoing apoptosis show a sequence of cardinal morphological features, including membrane blebbing, cellular shrinkage and condensation of chromatin (20). The intrinsic mitochondria-mediated pathway, when stimulated, leads to the release of cytochrome c from the mitochondria and to the activation of the death signal (21). Apoptotic signaling and execution through this pathway depends on caspases, or aspartate-specific cysteine 
proteases, which are the key effector molecules in the apoptotic process (22).

Although there are many therapeutic strategies to treat cancer, including chemotherapy, drug resistance have limited the successful outcomes in most cases. Recently, TNFrelated apoptosis-inducing ligand (TRAIL) and non-steroidal anti-inflammatory drugs (NSAIDs) have been found to sensitize Dox-induced apoptosis in various types of tumors $(23,24)$. In addition, the combination treatment of Dox and natural products dramatically augments the therapeutic effects against breast cancer, prostate cancer and hepatocellular carcinoma $(25,26)$. In this study, we investigated the ability of ABM to synergize the inhibitory action of Dox in human hepatocellular carcinoma HepG2 cell line. We also evaluated the molecular mechanisms underlying this synergistic effect and sought evidence of synergy between Dox and ABM.

\section{Materials and methods}

Materials. The human hepatocellular carcinoma cell line, HepG2 (ATCC HB-8065), was obtained from Korean Cell Line Bank (Seoul, Korea). Fetal bovine serum, penicillin G, streptomycin and RPMI-1640 were obtained from Gibco (Grand Island, NY, USA). Dox, acridine orange and 3-(4,5dimethylthiazol-2-yl)-2,5-diphenyltetrazolium bromide (MTT) were purchased from Sigma Chemical Co. (St. Louis, MO, USA). Cell-permeable inhibitor peptide (NFKB SN50) and BAY 11-7082 were obtained from Calbiochem (La Jolla, CA, USA). General caspase inhibitor z-VAD-fmk was purchased from BD Bioscience (San Diego, CA, USA). All other chemicals were of Sigma grade. Antibodies to caspase 3, p53, phospho-p53, NFкB p105/p50, NFкB p65 and horseradish peroxidase (HRP)-linked anti-rabbit IgG were obtained from Cell Signaling (Beverly, MA, USA). Antibodies to cytochrome c, Bax, Bcl-2, B-actin and HRP-linked goat antimouse IgG were purchased from Santa Cruz Biotechnology (Santa Cruz, CA, USA).

Mushroom extracts and the chemotherapeutic drug. The crude water-soluble polysaccharide, which was obtained from the fruiting body of ABM by hot water extraction and ethanol precipitation, was fractionated by DEAE-cellulose and Sepharose CL-6B column chromatography, as previously reported (27). The purified components of ABM primarily consisted of polysaccharide, which was B-glucan. ABM contained a level of endotoxin below the detection limits (0.0015 EU/ml) as assessed by an E-TOXATE kit (Sigma) (unpublished data). Dox was dissolved in $1 \mathrm{X}$ phosphatebuffered saline (PBS) for injection at a concentration of $5 \mathrm{mg} / \mathrm{ml}$ and stored in aliquots at $4^{\circ} \mathrm{C}$. Immediately before each experiment, serial dilutions of this drug were performed in culture media to obtain the required final concentrations.

Cell culture. HepG2 cells were cultured in RPMI-1640 medium supplemented with $10 \%$ heat-inactivated fetal bovine serum, $100 \mathrm{U} / \mathrm{ml}$ penicillin, and $100 \mu \mathrm{g} / \mathrm{ml}$ streptomycin. Cells were maintained at $37^{\circ} \mathrm{C}$ in a $5 \% \mathrm{CO}_{2}$ incubator, and the media were changed twice weekly.
In vitro cytotoxic assay; colorimetric MTT assay. The cytotoxicity of ABM and Dox on the viability of HepG2 cells was measured using the MTT assay, which relies on the ability of viable cells to metabolically reduce the tetrazolium salt MTT to a purple formazan product, which can be quantified colorimetrically (28). Briefly, cell suspensions $\left(2 \times 10^{5}\right.$ cells $\left./ \mathrm{ml}\right)$ were seeded in $96-$ well plates and incubated at $37^{\circ} \mathrm{C}$ to allow for cell attachment. After $48 \mathrm{~h}$, the cells were treated with serum-free medium containing the indicated additives. The plates were incubated for $1 \mathrm{~h}$ (day 0 ) and $72 \mathrm{~h}$ (day 3) at $37^{\circ} \mathrm{C}$. After the end of each exposure time, $50 \mu \mathrm{l}$ of the MTT stock solution $(5 \mathrm{mg} / \mathrm{ml})$ in serum-free medium were added to each well to reach a total reaction volume of $200 \mu \mathrm{l}$. After incubation for $2 \mathrm{~h}$ at $37^{\circ} \mathrm{C}$, the supernatants were aspirated. The formazan crystal in each well was dissolved in isopropyl alcohol and the absorbance was determined at $570 \mathrm{~nm}$ on a scanning multiwell spectrophotometer. The relative percentage of survival was calculated by dividing the absorbance of treated cells by that of the control in each experiment. Percent cytotoxicity was calculated using the following formula: percent cytotoxicity $=[1-$ (absorbance of experimental wells/absorbance of control wells)] $\mathrm{x}$ $100 \%$.

Cell morphology assessment. Cells $\left(2.5 \times 10^{5}\right)$ were subcultured for $48 \mathrm{~h}$ on coverslips in 6-well plates. After combination treatment of ABM $(100 \mu \mathrm{g} / \mathrm{ml})$ with Dox $(1 \mu \mathrm{g} / \mathrm{ml})$ for $72 \mathrm{~h}$, cell cytological morphology changes were observed using an Olympus optical microscope. Cells were fixed with $3.7 \%$ paraformaldehyde for $20 \mathrm{~min}$, washed with PBS, and stained with acridine orange $(5 \mu \mathrm{g} / \mathrm{ml})$ for $5 \mathrm{~min}$. After washing with PBS, cells were mounted under glass coverslips with Vectashield (Brunschwig, Amsterdam, The Netherlands) and observed. Photographs were taken under a fluorescence microscope (24).

Annexin V/propidium iodide staining. Apoptosis-mediated cell death of tumor cells was examined using a FITC-labeled annexin V/propidium iodide (PI) apoptosis detection kit (Molecular Probes, Eugene, OR, USA) according to the manufacturer's instructions. Briefly, cells were harvested by trypsinization, washed with PBS, and centrifuged to collect the cell pellet. The number of cells was adjusted to $1 \times 10^{6}$ cells $/ \mathrm{ml}$. Cells were then resuspended in binding buffer (10 mM HEPES, $140 \mathrm{mM} \mathrm{NaCl}, 2.5 \mathrm{mM} \mathrm{CaCl}_{2}, \mathrm{pH}$ 7.4), and stained with FITC-labeled annexin V and PI at room temperature for $15 \mathrm{~min}$ in the dark. Flow cytometric analysis was performed using a FACSCalibur flow cytometer (BectonDickinson, Mountain View, CA, USA) within $1 \mathrm{~h}$ after supravital staining. FITC-labeled annexin $\mathrm{V}$ was analyzed using excitation and emission setting of 488 and $535 \mathrm{~nm}$. PI was analyzed using excitation and emission setting of 488 and $575 \mathrm{~nm}$. For each flow cytometer run, 10,000 cells were required. The percentages of cells were calculated by Cell Quest software (Becton-Dickinson). The cells in the early stages of apoptosis were annexin V-positive and PI-negative; however, the cells in the late stages of apoptosis were both annexin V-and PI-positive. The apoptotic index (\%) was calculated as the sum of early and late apoptotic cells divided for the total number of events (29). 
Preparation of subcellular fractionation. The mitochondrial fraction was prepared using a mitochondria isolation kit (Sigma) according to the manufacturer's instructions. Briefly, after various treatments, HepG2 cells were harvested and resuspended in $0.65-2 \mathrm{ml}$ of lysis buffer per $2-5 \times 10^{7}$ cells. The homogenate was incubated on ice for $5 \mathrm{~min}$, two volumes of $1 \mathrm{X}$ extraction buffer were added, and the solution was centrifuged at $600 \mathrm{x} \mathrm{g}$ for $10 \mathrm{~min}$ at $4^{\circ} \mathrm{C}$. After centrifugation, the supernatant was transferred to fresh $1.5 \mathrm{ml}$ tubes and centrifuged at $11,000 \mathrm{x} \mathrm{g}$ for $10 \mathrm{~min}$ at $4^{\circ} \mathrm{C}$. The supernatant was removed, and the pellet was suspended in a CelLytic $\mathrm{M}$ cell lysis reagent with protease inhibitor cocktail $(1: 100$ $[\mathrm{v} / \mathrm{v}])$.

Nuclear extracts were prepared by lysing nuclei in a high salt buffer supplemented with protease and phosphatase inhibitors using a nuclear extraction kit (Panomics Inc., Fremont, CA, USA) according to the manufacturer's protocol. Protein concentrations were quantified by the Bio-Rad protein assay (Bio-Rad Laboratories, Hercules, CA, USA).

Western blot analysis. After treatment, cells were washed in $1 \mathrm{X}$ PBS and lysed in lysis buffer [10 mM Tris- $\mathrm{HCl}(\mathrm{pH} 7.5)$, $10 \mathrm{mM} \mathrm{NaH}{ }_{2} \mathrm{PO}_{4} / \mathrm{NaHPO}_{4}(\mathrm{pH} 7.5), 130 \mathrm{mM} \mathrm{NaCl}, 1 \%$ Triton X-100, $10 \mathrm{mM} \mathrm{NaPPi}, 1 \mathrm{mM}$ phenylmethylsulphonyl fluoride, $2 \mu \mathrm{g} / \mathrm{ml}$ pepstatin A] for $30 \mathrm{~min}$ on ice. Lysates were centrifuged at $12,000 \mathrm{x}$ g for $20 \mathrm{~min}$ at $4^{\circ} \mathrm{C}$. The supernatant was collected, and the protein content of the supernatant was measured using a Bio-Rad protein assay kit before analysis. The cytosolic, mitochondrial, or nuclear protein samples were loaded at $10 \mathrm{x} g$ of protein/lane, separated by sodium dodecyl sulfate-polyacrylamide gel electrophoresis in $10-15 \%$ gel, and transferred to polyvinylidene difluoride membranes (Immun-Blot PVDF membrane, $0.2 \mu \mathrm{m}$; BioRad). Membranes were blocked with $5 \%$ non-fat powdered milk in $1 \mathrm{X}$ Tris-buffered saline containing $0.1 \%$ Tween-20 (TBS-T) for $1 \mathrm{~h}$, and they were incubated with primary antibodies at $4^{\circ} \mathrm{C}$ overnight. Finally, the membranes were treated with HRP-linked secondary antibodies for $1 \mathrm{~h}$ at $4^{\circ} \mathrm{C}$. The membranes were washed with TBS-T after each antibody binding reaction. Detection of each protein was performed using an enhanced chemiluminescence kit (Millipore Co., Billerica, MA, USA) (29).

Assay for caspase 3 activities. After various treatments, HepG2 cells were lysed in $500 \mu 1$ lysis buffer consisting of $10 \mathrm{mM}$ Tris- $\mathrm{HCl}(\mathrm{pH} 7.5), 10 \mathrm{mM} \mathrm{NaH}{ }_{2} \mathrm{PO}_{4} / \mathrm{NaHPO}_{4}(\mathrm{pH}$ 7.5), $130 \mathrm{mM} \mathrm{NaCl}, 1 \%$ Triton $\mathrm{X}-100$, and $10 \mathrm{mM} \mathrm{NaPPi}$. Caspase 3 activity in the lysates was evaluated using a caspase assay kit (BD Bioscience) according to the manufacturer's instructions, with some modifications (30). For each sample, $50 \mu 1$ of the cell lysate, $5 \mu \mathrm{l}$ of Ac-DEVD-AMC $(1 \mathrm{mg} / \mathrm{ml}$; a synthetic fluorogenic substrate), and $50 \mu \mathrm{l}$ of reaction buffer [20 mM HEPES (pH 7.5), 10\% glycerol, and 2 mM DTT] were transferred to a 96-well plate, mixed and incubated at $37^{\circ} \mathrm{C}$ for $1.5 \mathrm{~h}$. Caspase 3 cleaves Ac-DEVD-AMC to release the fluorescent AMC. The release of AMC in the cell lysates was measured using the Fluoroskan Ascent FL with Ascent software version 2.6 (Thermo scientific, Langenselbold, Germany) using as excitation filter with a wavelength of $360 \mathrm{~nm}$ and an emission filter with a wavelength of $460 \mathrm{~nm}$.
Assay for caspase inhibitor activity. The cells were seeded at a density of $5 \times 10^{5}$ cells/well, and cultured for $48 \mathrm{~h}$ in RPMI1640 medium. The cells were pre-incubated with the indicated concentrations of $\mathrm{z}$-VAD-fmk for $2 \mathrm{~h}$, and they were treated with the combination treatment of ABM $(100 \mu \mathrm{g} / \mathrm{ml})$ and Dox $(1 \mu \mathrm{g} / \mathrm{ml})$ for $72 \mathrm{~h}$. The viability of HepG2 cells was measured using the MTT assay (30).

Dox accumulation assay. Cells $\left(2.5 \times 10^{5}\right)$ were subcultured on coverslip in 6-well plates and incubated overnight, after which additives were added for $24 \mathrm{~h}$. Subsequently, the culture medium was removed, and the cells washed three times with PBS. Cells were fixed in $3.7 \%$ paraformaldehyde for $10 \mathrm{~min}$ at room temperature, washed three times with PBS, and mounted under glass coverslip with Vectashield. The cells were observed, and photographs for Dox fluorescence were taken under fluorescence microscopy (31).

Statistical analysis. Data were expressed as means \pm standard error (SEM), and the results were taken from at least three independent experiments performed in triplicate. The data were analyzed by Student's t-test to evaluate significant differences. A level of $\mathrm{p}<0.05$ was regarded as statistically significant.

\section{Results}

$A B M$ and Dox, at a low dose, synergise to induce apoptosis in human hepatocellular carcinoma cells. To investigate the anti-tumor effect of ABM on hepatocellular carcinoma, we tested the effect of $\mathrm{ABM}$ or/and Dox treatment on human hepatocellular carcinoma cells. HepG2 cells were either left untreated, or treated with different doses of ABM or/and Dox for $72 \mathrm{~h}$. After treatment with ABM alone, a moderately dose-dependent growth-inhibitory effect on HepG2 cells was observed. A similar phenomenon was observed following Dox treatment. Interestingly, the combination of ABM and $1 \mu \mathrm{g} / \mathrm{ml}$ of Dox had a significantly $(\mathrm{p}<0.05)$ greater dosedependent inhibitory effect than that of ABM or Dox alone at comparable concentrations (Fig. 1A). To evaluate whether or not the growth-inhibitory effect of the combination treatment of ABM and Dox was associated with apoptosis, a doublestaining method using FITC-labeled annexin V and PI was performed. During the early stages of apoptosis, cells display phosphatidylserine on their outer cell membranes, which is readily detectable by annexin V. During the later stages of apoptosis, as the plasma membrane becomes increasingly permeable, PI can move across the cell membrane to bind to cellular DNA. Double staining the cells with annexin V and PI allowed us to detect apoptotic cells by flow cytometry. The combination of ABM $(100 \mu \mathrm{g} / \mathrm{ml})$ and Dox $(1 \mu \mathrm{g} / \mathrm{ml})$ had an apoptotic effect on the cells. Moreover, the growthinhibitory effect of the combination treatment on HepG2 cells was found to be time-dependent, because the inhibitory effect became gradually stronger with the passage of time after treatment; the most significant effect was observed at $72 \mathrm{~h}$ (Fig. 1B). To further confirm the cytotoxic synergy between ABM and Dox, we performed a morphology study. Cells in dishes supplemented with $100 \mu \mathrm{g} / \mathrm{ml}$ of ABM and $1 \mu \mathrm{g} / \mathrm{ml}$ of Dox became sparse, rounded and detached from 
A

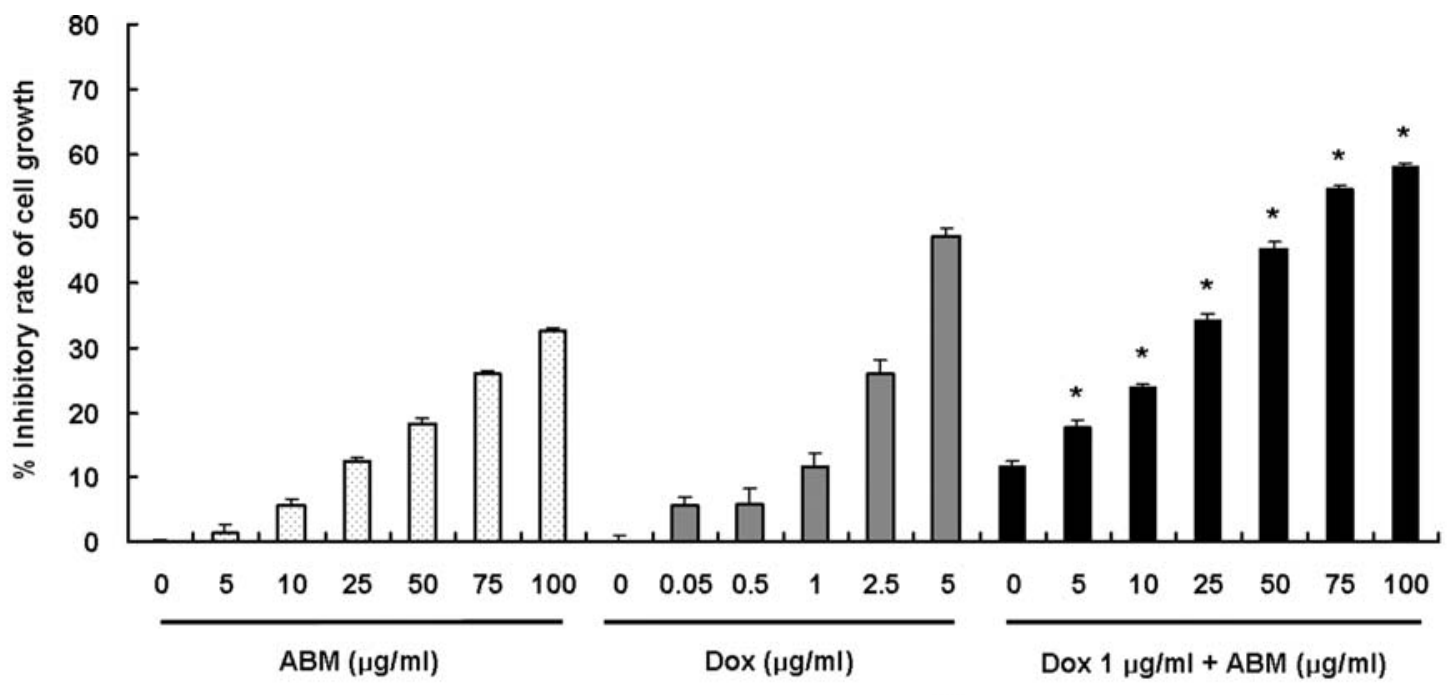

B
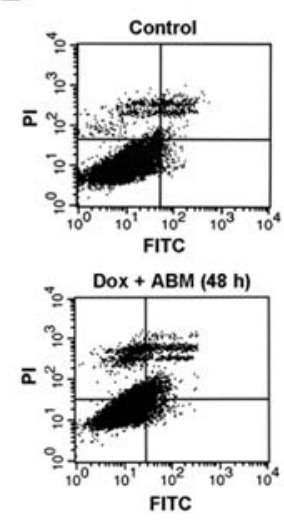
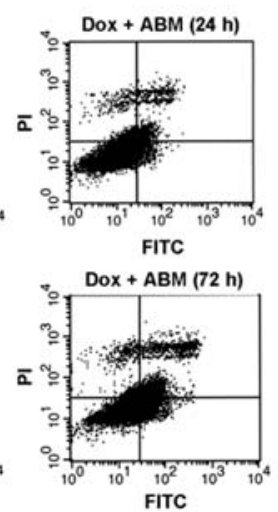

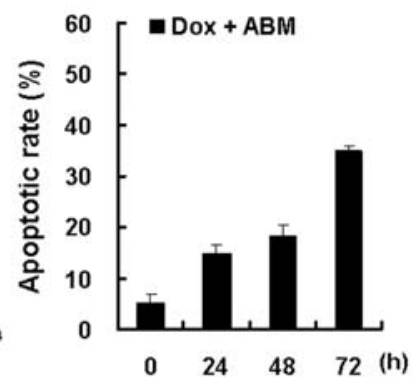

C

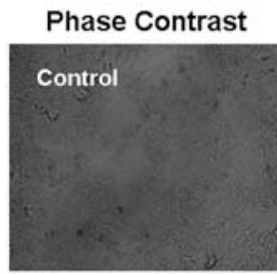

Dox + ABM

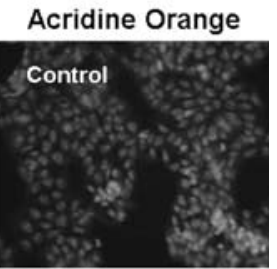

Dox + ABM

Figure 1. Synergistic cell growth inhibition and apoptosis in HepG2 cells treated with ABM in combination with Dox. (A) The concentration-dependent synergistic cell growth-inhibitory effect of various concentrations of ABM in combination with Dox. Cells were incubated with various concentrations of $\mathrm{ABM}$ or/and Dox for $72 \mathrm{~h}$. Cell viability was measured by the MTT reduction assay. Each value represents the mean \pm SE of three independent experiments. Significant differences were compared with the control at ${ }^{*} \mathrm{p}<0.05$ by Student's t-test. (B) Percentages of apoptotic cells after the combination treatment of $\operatorname{ABM}(100 \mu \mathrm{g} / \mathrm{ml})$ and Dox $(1 \mu \mathrm{g} / \mathrm{ml})$ in HepG2 cells at $0,24,48$ and $72 \mathrm{~h}$ were measured by the annexin V/PI flow cytometry analysis. (C) Morphological characteristics of HepG2 cells before and after the combination treatment. The HepG2 cells were treated with or without ABM (100 $\mu \mathrm{g} / \mathrm{ml})$ and Dox $(1 \mu \mathrm{g} / \mathrm{ml})$ for $72 \mathrm{~h}$ and stained with acridine orange. The cell morphology was observed under optical microscope (magnification, $\mathrm{x} 100)$ and fluorescence microscope (magnification, $\mathrm{x} 200$ ).

the dishes. We observed the normal morphology of druguntreated HepG2 cells by staining cells with acridine orange. In this case, cells exhibited a shape that contained tri- or multi-angles with abundant cytoplasma and large oval nuclei with dispersed chromatin. Combination-treated HepG2 cells had the typical morphology of apoptotic cells, including cell shrinkage, chromatin condensation and formation of apoptotic bodies (Fig. 1C). Overall, the results indicated that low doses of ABM and Dox synergistically enhanced Dox-induced apoptosis in HepG2 cells. We conducted further experiments to understand the molecular mechanism by which ABM sensitizes Dox-induced apoptosis in HepG2 cells.

Involvement of caspases in the synergistic effect of ABM and Dox. The caspase family plays an important role in many types of apoptosis, including Dox-induced apoptosis (32). At high doses, Dox can induce apoptosis, possibly through caspase-mediated apoptotic signaling $(33,34)$. To study the mechanisms of the combination treatment of ABM and Dox, we examined whether or not caspase was involved in the synergistic induction of apoptosis. Upon activation, caspases are cleaved into small, active forms (22). Therefore, we analyzed changes in the levels of pro-caspase 3 by Western blot analysis. Treatment with ABM or Dox alone did not induce caspase 3 cleavage. In comparison, pro-caspase 3 cleavage was induced in response to combination treatment with $\mathrm{ABM}$ and Dox (Fig. 2A). To further determine the activation of caspase 3 by the combination treatment of ABM and Dox, the activity of caspase 3 was analyzed using a commercial caspase 3 assay kit. The combination treatment significantly $(\mathrm{p}<0.05)$ increased the activity of caspase 3 (Fig. 2B). To confirm whether or not the apoptosis induced by the combination treatment occurs via the caspase-dependent pathway, a general caspase inhibitor z-VAD-fmk was added to the combination treatment. Pretreatment of caspase inhibitor significantly $(\mathrm{p}<0.05)$ reduced cytotoxicity by the combination treatment in a dose-dependent manner (Fig. 2C). Thus, these results indicated that low doses of ABM and Dox could synergistically enhance caspase activity in HepG2 cells.

Combination treatment-mediated apoptosis via the mitochondria-mediated apoptotic pathway. The mitochondria- 
A

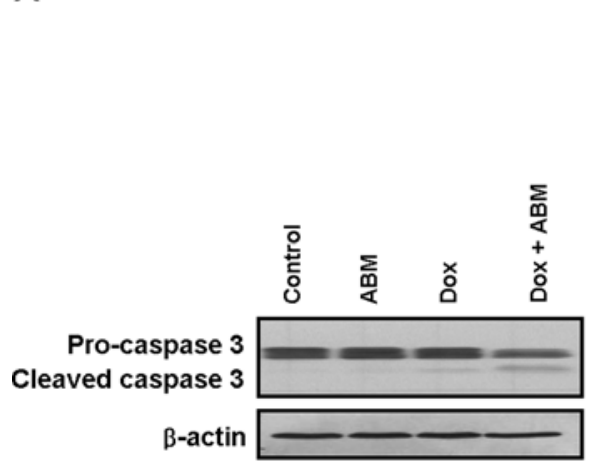

B

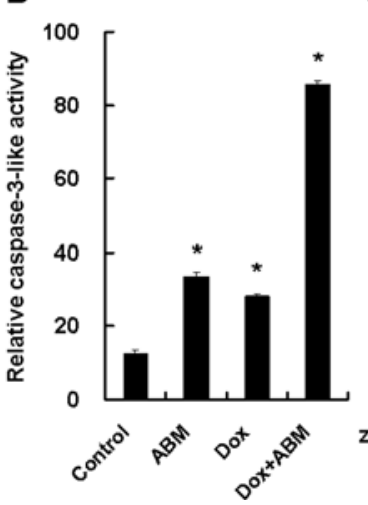

C

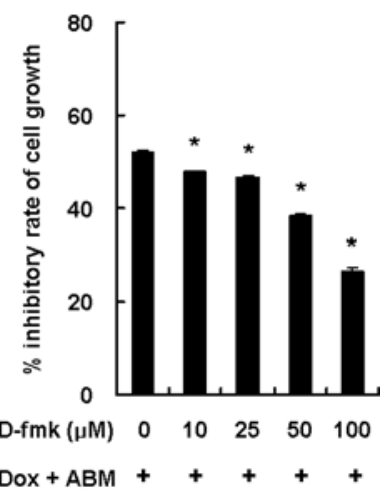

Figure 2. Activation of caspase 3 following the combination treatment of ABM and Dox. (A) After treating with $\mathrm{ABM}(100 \mu \mathrm{g} / \mathrm{ml}), \mathrm{Dox}(1 \mu \mathrm{g} / \mathrm{ml}), \mathrm{or} \mathrm{ABM}$ plus Dox for $72 \mathrm{~h}, \mathrm{HepG} 2$ cells were harvested, and lysates were prepared. The cleavage of pro-caspase 3 and existence of the activated form of caspase 3 were determined by Western blot analysis. Equal loading of total proteins in each sample was verified by $\beta$-actin expression. (B) Effect of the treatment of ABM $(100 \mu \mathrm{g} / \mathrm{ml})$, Dox $(1 \mu \mathrm{g} / \mathrm{ml})$, or ABM plus Dox on caspase 3-like activity in HepG2 cells. After treatment for $72 \mathrm{~h}$, preparation of cell lysates and measurement of caspase 3-like activity was performed. Each value represents the mean \pm SE of three independent experiments. Significant differences were compared with the control at ${ }^{*} \mathrm{p}<0.05$ by Student's t-test. (C) Effects of the caspase inhibitor $\mathrm{z}$-VAD-fmk on the synergistic cell growth inhibition in HepG2 cells treated with ABM plus Dox. HepG2 cells were pre-incubated with the indicated concentrations of $\mathrm{z}$-VAD-fmk for $2 \mathrm{~h}$ then treated with ABM $(100 \mu \mathrm{g} / \mathrm{ml})$ plus Dox $(1 \mu \mathrm{g} / \mathrm{ml})$ for $72 \mathrm{~h}$. Cell viability was measured by the MTT reduction assay. Each value represents the mean \pm SE of three independent experiments. Significant differences were compared with the control at * $\mathrm{p}<0.05$ by Student's t-test.

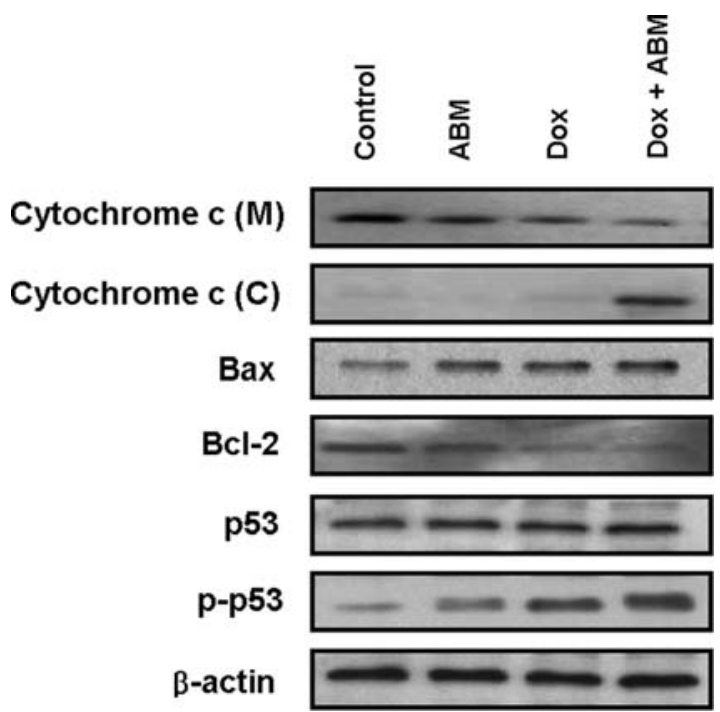

Figure 3. Altered expression of apoptotic-related proteins in HepG2 cells treated with ABM, Dox, or ABM plus Dox. After treating with ABM $(100 \mu \mathrm{g} / \mathrm{ml})$, Dox $(1 \mu \mathrm{g} / \mathrm{ml})$, or ABM plus Dox for $72 \mathrm{~h}$, HepG2 cells were harvested, and lysates were prepared. The mitochondrial (M) and cytosolic (C) fraction from the indicated additive-treated cells were isolated and analyzed for the expression of cytochrome c using Western blot analysis. The levels of Bax, Bcl-2, p53 and phospho-p53 were assessed using Western blot analysis. Equal loading of total proteins in each sample was verified by $ß$-actin expression.

mediated apoptotic pathway plays a critical role in apoptosis. The intrinsic apoptotic pathway is dependent on the balance between Bcl-2 and Bax affecting the release of cytochrome c and second mitochondria-derived activator of caspase (19). To examine whether the combination treatment of ABM and Dox contributed to mitochondrial damage and to the activation of the downstream apoptosis cascade, the release of cytochrome c into the cytosolic fraction (an indicator of compromised mitochondrial integrity) was assessed using
Western blot analysis. Cytochrome c was present in the cytosolic fraction and absent in the mitochondrial fraction isolated from the cells treated with the combination of ABM and Dox (Fig. 3). Bcl-2 family proteins serve as critical regulators of the mitochondria-mediated apoptosis pathway, functioning as either inhibitors (e.g., Bcl-2, Bcl-XL, Bcl-W and Mcl-2) or promoters (e.g., Bax, Bid, Bad and Bim) of cell death (35). To further confirm that mitochondrial apoptotic events were involved in the combination treatment-induced apoptosis, we analyzed changes in the levels of Bax and Bcl-2 by Western blot analysis. The combination treatment of $\mathrm{ABM}$ and Dox increased expression of the pro-apoptotic protein Bax, but decreased expression of the anti-apoptotic protein Bcl-2 in HepG2 cells (Fig. 3). The efficacy of Dox on cancer cells is in large part p53-dependent $(33,34)$. As a result of the effect of p53 on the combination treatmentinduced apoptosis using Western blot analysis, the phosphorylation of $\mathrm{p} 53$, a modulator of Bax, was affected in co-treated HepG2 cells (Fig. 3). Overall, these results demonstrated that the intrinsic apoptotic pathway was involved in the combination treatment-induced apoptosis in HepG2 cells.

$A B M$ increased the intracellular accumulation and retention of Dox. Dox is DNA-damaging agent. DNA damage is caused by ATM and Chk2 kinases, which phosphorylate and stabilize p53, allowing it to function as a transcription factor inducing apoptosis (36). To understand the enhancement of the phosphorylation of p53 in the combination treatment of ABM and Dox, we investigated the effect of ABM on intracellular accumulation of Dox. Dox is an auto-fluorescent compound that allows for the visualization of its intracellular presence by fluorescence microscopy. To investigate the effect of ABM on intracellular accumulation of Dox, we examined the fluorescence of intracellular-accumulated Dox in HepG2 cells after incubation for $24 \mathrm{~h}$ in the absence or presence of ABM $(100 \mu \mathrm{g} / \mathrm{ml})$. The intracellular fluorescence, which was primarily visible in the nuclei, was remarkably higher in cells 
A

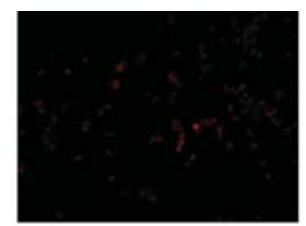

Dox $1 \mu \mathrm{g} / \mathrm{ml}$

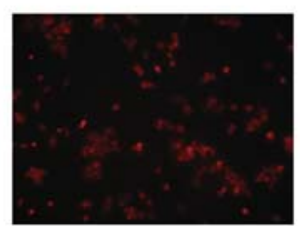

Dox $2.5 \mu \mathrm{g} / \mathrm{ml}$

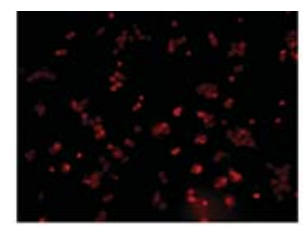

Dox $1 \mu \mathrm{g} / \mathrm{ml}$ + ABM $100 \mu \mathrm{g} / \mathrm{ml}$

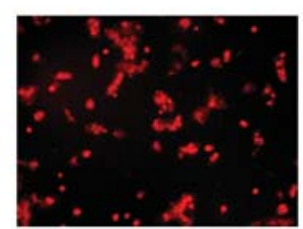

Dox $2.5 \mu \mathrm{g} / \mathrm{ml}$ + ABM $100 \mu \mathrm{g} / \mathrm{ml}$

B

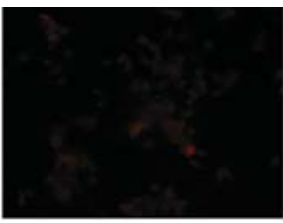

Dox $1 \mu \mathrm{g} / \mathrm{ml}$

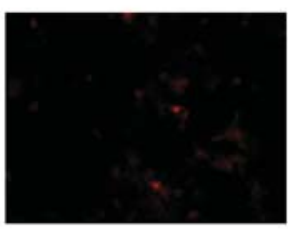

Dox $2.5 \mu \mathrm{g} / \mathrm{ml}$

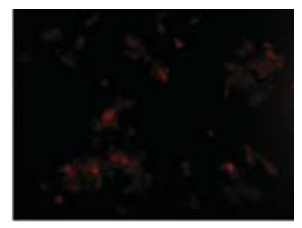

Dox $1 \mu \mathrm{g} / \mathrm{ml}$ + ABM $100 \mu \mathrm{g} / \mathrm{ml}$

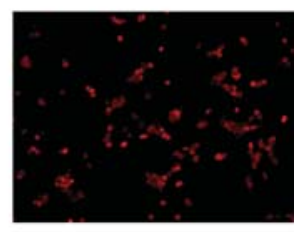

Dox $2.5 \mu \mathrm{g} / \mathrm{ml}+$ ABM $100 \mu \mathrm{g} / \mathrm{ml}$

Figure 4. Effect of ABM on the intracellular accumulation and retention of Dox. (A) Intracellular Dox accumulation: fluorescent microscopic pictures of HepG2 cells that were incubated for $24 \mathrm{~h}$ in a medium containing Dox (1 and $2.5 \mu \mathrm{g} / \mathrm{ml}$ ) in combination with ABM (100 $\mu \mathrm{g} / \mathrm{ml})$. Magnification, x200. (B) Intracellular Dox retention: fluorescent microscopic pictures of HepG2 cells treated with Dox (1 and $2.5 \mu \mathrm{g} / \mathrm{ml})$ for $24 \mathrm{~h}$, followed by $24 \mathrm{~h}$ incubation in control medium or medium containing ABM $(100 \mu \mathrm{g} / \mathrm{ml})$. Magnification, $\mathrm{x} 200$.

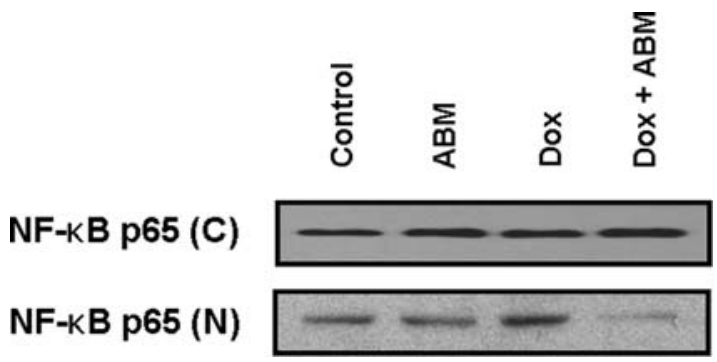

Figure 5. Suppression of NFKB subunit p65 translocation following combination treatment with ABM and Dox. After treating with ABM $(100 \mu \mathrm{g} / \mathrm{ml})$, Dox $(1 \mu \mathrm{g} / \mathrm{ml})$, or ABM plus Dox for $24 \mathrm{~h}$, the nuclear $(\mathrm{N})$ and cytosolic (C) fractions from the indicated additive-treated cells were isolated and analyzed for the expression of p65 using Western blot analysis.

that were co-treated with ABM (Fig. 4A). To determine the effect of $\mathrm{ABM}$ on the intracellular retention of Dox, HepG2 cells were incubated for $24 \mathrm{~h}$ with Dox (1 and $2.5 \mu \mathrm{g} / \mathrm{ml})$ followed by incubation for an additional $24 \mathrm{~h}$ in a control medium or in a medium containing ABM $(100 \mu \mathrm{g} / \mathrm{ml})$. Cells treated with $\mathrm{ABM}$ contained more Dox than those that were incubated in the control medium during the second $24 \mathrm{~h}$ culture period (Fig. 4B). Therefore, these results indicated that ABM enhanced Dox-induced cytotoxicity in HepG2 cells was due to an increase in intracellular Dox accumulation.

The combination treatment of $A B M$ and Dox suppress $N F \kappa B$ translocation. NFKB has been shown to be involved in chemoresistance in different cell types, suggesting a possible role of this transcription factor in the chemosensitising effect of agents $(5,7)$. To unravel the molecular mechanisms involved in Dox accumulation, we examined the effect of the combination treatment of $\mathrm{ABM}$ and Dox on the translocation of NFKB by Western blot analysis using an NFKB subunit p65 antibody. Dox strongly induced the translocation of nuclear p65 into the nuclei; however, the combination treatment remarkably inhibited Dox-enhanced nuclear p65 translocation (Fig. 5).
The inhibition of NFKB activation was involved in modulating intracellular Dox accumulation. To further investigate the role of NFKB in the enhanced anti-tumor efficacy of Dox, we examined the effects of Dox in the absence or presence of NFкB inhibitors, BAY 11-7082 $(10 \mu \mathrm{M})$ or SN50 $(25 \mu \mathrm{M})$, on HepG2 cell growth and intracellular Dox accumulation. The NFkB inhibitors, BAY 11-7082 or SN50, had a greater dose-dependent anti-proliferative effect than that of Dox alone, and they also increased intracellular Dox accumulation (Fig. 6A and B). Furthermore, Western blot analysis of another NFkB subunit p50 in nuclear $(\mathrm{N})$ and cytosolic (C) extracts from HepG 2 cultured for $24 \mathrm{~h}$ in the treatment with Dox (alone or in combination with BAY 11-7082 or SN50) showed that BAY 11-7082 and SN50 inhibited Dox-enhanced nuclear p50 translocation (Fig. 6C). Thus, these results showed that the inhibition of NFKB activation might be involved in modulating intracellular Dox accumulation.

\section{Discussion}

In this study, we showed that low doses of ABM and Dox synergize to induce apoptosis in human hepatocellular carcinoma HepG2 cells. Caspase 3 was activated in the apoptotic process induced by the combination treatment of $\mathrm{ABM}$ and Dox. The suppression of caspase activity by a general caspase inhibitor z-VAD-fmk confirmed that the promotion of apoptosis by combination treatment involved a caspase-dependent pathway. Moreover, reducing the ratio of $\mathrm{Bcl}-2 / \mathrm{Bax}$ protein expression through the phosphorylation of p53 induced the release of cytochrome $\mathrm{c}$ from the mitochondria to cytosol. Therefore, we have been able to show that the mitochondriamediated apoptotic pathway was involved in the combination treatment-induced apoptosis in HepG2 cells.

Cancer progression is partially affected by the development of cancer cell resistance to apoptosis induced by chemotherapeutic drugs. NFkB has been shown to be involved in chemoresistance in different cell types, suggesting a possible role of this transcription factor in the chemosen- 
A

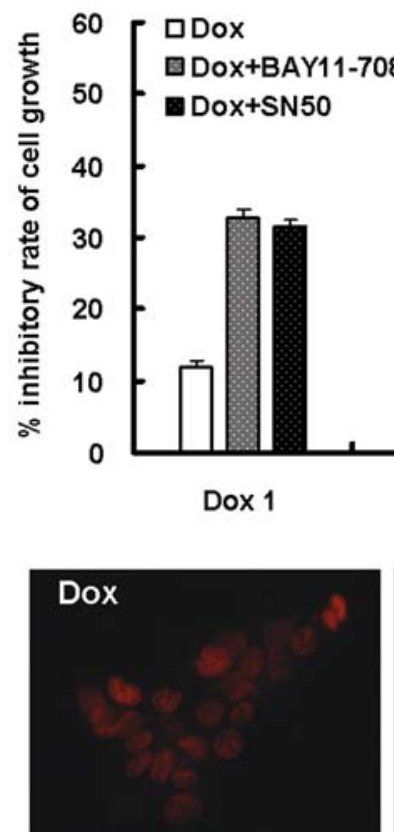

C

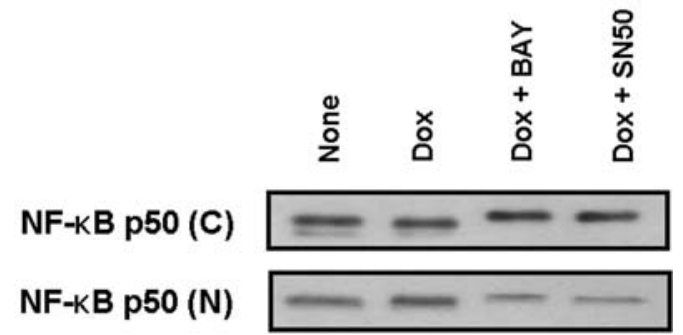

Dox 2.5
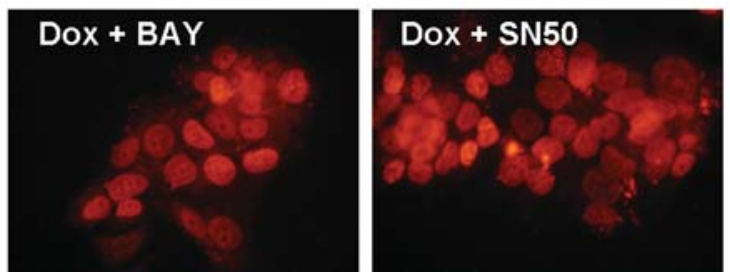

Figure 6. Effect of Dox, alone or in combination with NFkB inhibitor on HepG2 cell growth and effect of NFkB inhibitor on intracellular Dox accumulation (A) A dose-dependent synergistic cell growth-inhibitory effect of BAY 11-7082 or SN50 in combination with Dox. HepG2 cells were pre-incubated with BAY 11-7082 $(10 \mu \mathrm{M})$ or SN50 $(25 \mu \mathrm{M})$ for $2 \mathrm{~h}$ then treated with Dox $(1$ and $2.5 \mu \mathrm{g} / \mathrm{ml})$ for $72 \mathrm{~h}$. Cell viability was measured by the MTT reduction assay. Each value represents the mean $\pm \mathrm{SE}$ of three independent experiments. (B) Fluorescent microscopic pictures of HepG2 cells that were incubated for $24 \mathrm{~h}$ in a medium containing Dox $(1 \mu \mathrm{g} / \mathrm{ml})$ or in combination with BAY 11-7082 $(10 \mu \mathrm{M})$ or SN50 $(25 \mu \mathrm{M})$. Magnification, $\mathrm{x} 400$. (C) Suppression of the NFkB subunit p50 translocation following combination treatment with NFkB inhibitor and Dox. HepG2 cells were pre-incubated with BAY $11-7082$ (10 $\mu \mathrm{M}$ ) or SN50 $(25 \mu \mathrm{M})$ for $2 \mathrm{~h}$ then treated with Dox $(1 \mu \mathrm{g} / \mathrm{ml})$ for $24 \mathrm{~h}$. The nuclear $(\mathrm{N})$ and cytosolic $(\mathrm{C})$ fractions from the indicated additive-treated cells were isolated and analyzed for the expression of p50 using Western blot analysis.

sitising effect of drugs $(5,7)$. In this study, ABM increased the intracellular accumulation and retention of Dox. We also showed that, like ABM, NFKB inhibitors (BAY 11-7082 or SN50) increased the intracellular accumulation of Dox and augmented the Dox-induced cytotoxicity mediated via suppression of NFKB activity. Therefore, the combination treatment of low doses of ABM and Dox, which enhanced chemosensitivity by suppression of NFKB translocation, would have similar implications for the treatment of patients with HCCs.

In response to diverse stimuli, pro-apoptotic Bcl-2 family proteins such as Bax initiate the intrinsic apoptosis pathway by forming channels on assimilating into the mitochondria, thus increasing outer mitochondrial membrane permeability, and thereby facilitating the release of cytochrome $\mathrm{c}$ and other pro-apoptotic factors from the mitochondrial intermembrane space. Released cytochrome c forms an apoptosome complex with Apaf-1, which activates caspase 9, and in turn, its downstream caspase 3 , resulting in the morphological features of apoptosis (22). Dox is DNA-damaging agent. DNA damage is caused by ATM and Chk2 kinases, which phosphorylate and stabilize p53, allowing it to function as a transcription factor inducing apoptosis (36). The efficacy of a low dose of Dox on cancer cells is in large part p53-dependent $(33,34)$. It was found that p53 mediated apoptosis by transcriptionally regulating many other genes, including Bax, Apaf-1, Fas, or killer/DR5 (36). In addition, recent studies support a transcriptionally independent pathway involving localization of p53 to the mitochondria, followed by binding and inhibi- tion of Bcl-xL and/or Bcl-2 or by activating Bax directly (37). In agreement with this, the combination treatment of $\mathrm{ABM}$ and Dox upregulated the phosphorylation of p53, increased the expression of the pro-apoptotic protein Bax, and decreased the expression of anti-apoptotic Bcl-2, increased the release of cytochrome $\mathrm{c}$ from the mitochondria to cytosol, and subsequently activated caspase 3. A universal caspase inhibitor blocked this synergistic cytotoxic effect on HepG2 cells, further suggesting the involvement of caspase activity in the cytotoxicity rendered by the combination treatment with ABM and Dox. Therefore, these results support the involvement of the intrinsic mitochondria-mediated apoptotic pathway in combination treatment-induced apoptosis in HepG2 cells.

One feature that cytotoxic treatments of cancer have in common is their activation of the transcription factor $\mathrm{NF}_{\kappa} \mathrm{B}$, which suppresses the apoptotic potential of chemotherapeutic drugs and contributes to resistance $(5,6)$. Inhibition of $\mathrm{NF \kappa B}$ translocation has been implicated in enhanced chemosensitivity of chemotherapeutic drugs (7). Using Western blot analysis we found that combination treatment with $\mathrm{ABM}$ and Dox could inhibit NFKB nuclear translocation, where Dox increased it. To further confirm the role of $N F \kappa B$ in the enhanced cytotoxic efficacy of Dox, we combined NFkB inhibitors BAY 11-7082 or SN50 with Dox in the MTT and fluorescent Dox accumulation assays. NFkB inhibitors inhibited Dox-enhanced p50 nuclear translocation in Western blot analysis, increased the cytotoxic effect of Dox in the MTT assay in a dose-dependent manner, and increased the intracellular accumulation of Dox. The molecular mechanism 
linking inhibition of NFKB activity with enhanced Dox accumulation may be associated with the membrane-related actions of Dox and the decrease high basal expression of multi-drug resistance gene and transglutaminase (38-40).

In conclusion, chemotherapeutic resistance to drugs is a major obstacle to the successful treatment of human hepatocellular carcinoma. We have demonstrated that ABM acts as an enhancer to sensitize Dox-mediated apoptotic signaling by enhancing intracellular Dox accumulation via the inhibition of NFKB activity. Therefore, ABM, when combined with low doses of Dox, has the potential to provide more efficient therapeutic effects against drug-resistant human hepatocellular carcinoma.

\section{References}

1. Falkson G, MacIntyre JM and Moertel CG: Primary liver cancer. Cancer 54: 977-980, 1994.

2. Llovet JM: Updated treatment approach to hepatocellular carcinoma. J Gastroenterol 40: 225-235, 2005.

3. Hochster HS, Green MD, Speyer J, Fazzini E, Blum R and Muggia FM: 4'Epidoxorubicin (epirubicin): activity in hepatocellular carcinoma. J Clin Oncol 3: 1535-1540, 1985.

4. Kruh GD and Goldstein LJ: Doxorubicin and multidrug resistance. Curr Opin Oncol 5: 1029-1034, 1993.

5. Gangadharan C, Thoh M and Manna SK: Inhibition of constitutive activity of nuclear transcription factor kappaB sensitizes doxorubicin-resistant cells to apoptosis. J Cell Biochem 107: 203-213, 2009.

6. Liu P, Kimmoun E, Legrand A, Sauvanet A, Degott C, Lardeux B and Bernuau D: Activation of NF-kappaB, Ap-1 and STAT transcription factor is a frequent and early event in human hepatocellular carcinomas. J Hepatol 37: 63-71, 2002.

7. Nakanishi $\mathrm{C}$ and Toi M: Nuclear factor $-\kappa \mathrm{B}$ inhibitors as sensitizers to anticancer drugs. Nat Rev Cancer 5: 297-309, 2005.

8. Pahl HL: Activators and target genes of Rel/NF-кB transcription factors. Oncogene 18: 6853-6866, 1999.

9. Siebenlist U, Franzoso G and Brown K: Structure, regulation and function of NF-kappaB. Annu Rev Cell Biol 10: 405-455, 1994.

10. Mori N, Yamada Y, Ikeda S, Yamasaki Y, Tsukasaki K, Tanaka Y, Tomonaga M, Yamamoto N and Fujii M: Bay 11-7082 inhibits transcription factor NF- $\mathrm{KB}$ and induces apoptosis of HTLV-Iinfected T-cell lines and primary adult T-cell leukemia cells. Blood 100: 1828-1834, 2002.

11. Lin YZ, Yao SY, Veach RA, Torgerson TR and Hawiger J: Inhibition of nuclear translocation of transcription factor NFkappaB by a synthetic peptide containing a cell membranepermeable motif and nuclear localization sequence. J Biol Chem 270: $14255-14258,1995$.

12. Novak M and Vetvicka V: Beta-glucans, history, and the present: Immunomodulatory aspects and mechanisms of action. J Immunotoxicol 5: 47-57, 2008

13. Kobayashi H, Yoshida R, Kanada Y, Fukuda Y, Yagyu T, Inagaki K, Kondo T, Kurita N, Suzuki M, Kanayama N and Terao T: Suppressing effects of daily oral supplementation of beta-glucan extracted from Agaricus blazei Murill on spontaneous and peritoneal disseminated metastasis in mouse model. J Cancer Res Clin Oncol 131: 527-538, 2005.

14. Chihara G, Maeda Y, Hamuro J, Sasaki T and Fukuoka F: Inhibition of mouse sarcoma 180 by polysaccharides from Lentinus edodes (Berk.) sing. Nature 222: 687-688, 1969.

15. Wan JM, Sit WH and Louie JC: Polysaccharopeptide enhances the anticancer activity of doxorubicin and etoposide on human breast cancer cells ZR-75-30. Int J Oncol 32: 689-699, 2008.

16. Ng TB and Wang HX: Pharmacological actions of Cordyceps, a prized folk medicine. J Pharm Pharmacol 57: 1509-1520, 2005 .

17. Jin CY, Choi YH, Moon DO, Park C, Park YM, Jeong SC, Heo MS, Lee TH, Lee JD and Kim GY: Induction of G2/M arrest and apoptosis in human gastric epithelial AGS cells by aqueous extract of Agaricus blazei. Oncol Rep 16: 1349-1355, 2006.
18. Yu CH, Kan SF, Shu CH, Lu TJ, Sun-Hwang L and Wang PS: Inhibitory mechanisms of Agaricus blazei Murill on the growth of prostate cancer in vitro and in vivo. J Nutr Biochem 20: 753-764, 2009.

19. Ghobrial IM, Witzig TE and Adjei AA: Targeting apoptosis pathways in cancer therapy. CA Cancer J Clin 55: 178-194, 2005.

20. Saraste A and Pulkki K: Morphologic and biochemical hallmarks of apoptosis. Cardiovasc Res 45: 528-537, 2000.

21. Scorrano L: Opening the doors to cytochrome c: Changes in mitochondrial shape and apoptosis. Int J Biochem Cell Biol 41: 1875-1883, 2009.

22. Cohen GM: Caspases: the executioners of apoptosis. Biochem J 326: 1-16, 1997.

23. Wu X, Kakehi Y, Mizutani Y, Kamoto T, Kinoshita H, Isogawa Y, Terachi T and Ogawa O: Doxorubicin enhances TRAIL-induced apoptosis in prostate cancer. Int J Oncol 20: 949-954, 2002.

24. Pan YY, Xu SP, Jia XY, Xu HQ, Zhang Y, Rui LX and Wei W: Combination of cyclooxygenase-2 inhibitor and doxorubicin increases the growth inhibition and apoptosis in human hepatocellular carcinoma cells. Exp Oncol 29: 23-29, 2007.

25. Collins L, Zhu T, Guo J, Xiao ZJ and Chen CY: Phellinus linteus sensitises apoptosis induced by doxorubicin in prostate cancer. Br J Cancer 95: 282-288, 2006.

26. Pinmai K, Chunlaratthanabhorn S, Ngamkitidechakui C, Soonthornchareon N and Hahnvajanawong C: Synergistic growth inhibitory effects of Phyllanthus emblica and Terminalia bellerica extracts with conventional cytotoxic agents: Doxorubicin and cisplatin against human hepatocellular carcinoma and lung cancer cells. World J Gastroenterol 14: 1491-1497, 2008.

27. Lee JS, Kwon JS, Yun JS, Pahk JW, Shin WC, Lee SY and Hong EK: Structural characterization of immunostimulating polysaccharide from cultured mycelia of Cordyceps militaris. Carbohydr Polym 80: 1011-1017, 2010.

28. Lee JS, Cho JY and Hong EK: Study on macrophage activation and structural characteristics of purified polysaccharides from the liquid culture broth of Hericium erinaceus. Carbohydr Polym 78: 162-168, 2009.

29. Lee JS and Hong EK: Hericium erinaceus enhances doxorubicin-induced apoptosis in human hepatocellular carcinoma cells. Cancer Lett: doi:10.1016/j.canlet.2010.05.006 (E-pub ahead of print). 2010.

30. Feng G and Kaplowitz N: Colchicine protects mice from the lethal effects of an agonistic anti-Fas antibody. J Clin Invest 105: 329-339, 2000.

31. van Wijngaarden J, van Beek E, van Rossum G, van der Bent C, Hoekman K, van der Pluijm G, van der Pol MA, Broxterman HJ, van Hinsbergh VW and Lowik CW: Celecoxib enhances doxorubicin-induced cytotoxicity in MDA-MB231 cells by NF-kBmediated increase of intracellular doxorubicin accumulation. Eur J Cancer 43: 433-442, 2007.

32. Thornberry NA and Lazebnik Y: Caspases: enemies within. Science 281: 1312-1316, 1998.

33. Hannun YA: Apoptosis and the dilemma of cancer chemotherapy. Blood 89: 1845-1853, 1997.

34. Los M, Herr I, Friesen G, Fulda S, Schulze-Osthoff K and Lipkowitz S: Cross-resistance of CD95 and drug-induced apoptosis as a consequence of deficient activation of caspases (ICE/Ced-3 proteases). Blood 90: 3118-3129, 1997.

35. Gross A, McDonnell JM and Korsmeyer SJ: Bcl-2 family members and the mitochondria in apoptosis. Genes Dev 13: 1899-1911, 1999.

36. Schuler M and Green DR: Mechanisms of p53-dependent apoptosis. Biochem Soc Trans 7: 684-688, 2001.

37. Chipuk JE and Green DR: p53's believe it or not: Lessons on transcription-independent death. J Clin Immunol 23: 355-361, 2003.

38. Dimanche-Boitrel MT, Meurette O, Rebillard A and Lacour A: Role of early plasma membrane events in chemotherapyinduced cell death. Drug Resist Updat 8: 5-14, 2005.

39. Deng L, Lin-Lee YC, Claret FX and Kuo MT: 2-Acetylaminofluorene upregulates rat mdr1b expression through generating reactive oxygen species that activate NF-kappa B pathway. J Biol Chem 276: 413-420, 2001

40. Kuo MT, Liu Z, Wei Y, Lin-Lee YC, Tatebe S, Mills GB and Unate H: Induction of human MDR1 gene expression by 2acetylaminofluorene is mediated by effectors of the phosphoinositide 3-kinse pathway that activate NF-kappaB signaling. Oncogene 21: 1945-1954, 2002. 